\title{
Self-Reported Food Safety Practices and Associated Factors Among Health Extension Model and Non-Model Households in Northeastern Ethiopia: A Comparative Cross-Sectional Study
}

\author{
Awoke Keleb (D), Ayechew Ademas (D), Tadesse Sisay, Metadel Adane (D) \\ Department of Environmental Health, College of Medicine and Health Sciences, Wollo University, Dessie, Ethiopia \\ Correspondence: Awoke Keleb, Tel +251913117382, Email kalebawoke@gmail.com
}

\begin{abstract}
Purpose: Eating contaminated food continues to cause numerous food-borne diseases globally. Understanding the causes of poor food safety practices is key to preventing food-borne diseases. Therefore, this study aimed to assess the prevalence of food safety practices and associated factors among health extension model and non-model households in Kombolcha, Ethiopia.

Methods: A comparative cross-sectional study was conducted among 327 model households and 329 non-model households in Kombolcha. Four kebeles were selected randomly from a total of 12 kebeles, followed by a systematic random sampling method to select a total of 656 households. The data were collected through face-to-face interviews with household heads and observations from April 15 to May 15, 2021. Data were entered into EpiData version 3.1 and analyzed using SPSS version 25.0. Determinants of food safety practices were determined by using multivariable logistic regression model at a $p$-value $<0.05$.

Results: The overall prevalence of food safety practices was $44.7 \%$ (95\% CI: $40.5-48.4 \%$ ), of which $57.8 \%$ (95\% CI: 53.0-63.1\%) were model and 31.6\% (95\% CI: 26.5-36.7\%) were non-model households, with significant variation among household types. Being a model household (AOR=2.99; 95\% CI: 1.98-4.52), having a female household head (AOR=3.13; 95\% CI: 2.13-4.59), proper solid waste management $(\mathrm{AOR}=2.32 ; 95 \% \mathrm{CI}: 1.54-3.48)$, good knowledge of food safety ( $\mathrm{AOR}=2.05 ; 95 \% \mathrm{CI}$ : 1.43-3.03), and good attitude $(\mathrm{AOR}=1.74 ; 95 \% \mathrm{CI}: 1.22,2.49)$ were significant predictors of good food safety practices.

Conclusion: The prevalence of good food safety practices was not satisfactory. Being a model household, having a female household head, proper solid waste management, good knowledge, and good attitude were significantly associated with good food safety practices. Therefore, the identified modifiable factors are potential areas of intervention to enhance good food safety practices.
\end{abstract}

Keywords: food safety practices, health extension model, non-model

\section{Introduction}

Food infection and poisoning occur as a result of people eating food contaminated by microorganisms such as bacteria, viruses, and other food-borne pathogens, ${ }^{1}$ or their toxins, which can pose a threat to the health of consumers. ${ }^{2}$ Contamination is caused by improper preservation methods, unsanitary handling and storage, cross-contamination of food contact surfaces, or unhealthy practices during preparation. ${ }^{3,4}$ This can lead to large-scale outbreaks of food-borne illness and poisoning, often accompanied by high mortality. ${ }^{5}$

Food-borne diseases (FBDs) are responsible for significant morbidity and mortality. It is well known that food-borne hazards can cause more than 200 acute and chronic diseases, from gastrointestinal infections to cancer. ${ }^{6}$ Decreasing the risks from food safety hazards is a basic responsibility of any household or production business, regardless of its size. ${ }^{3,7}$

Food-borne-related illnesses have increased over the years, and negatively affect the health and well-being of people globally, and especially in developing nations, ${ }^{8}$ but evidence on FBD in low- and middle-income countries is still limited. ${ }^{9}$ Consumption of unsafe food not only results in public health problems but also has economic consequences 
owing to absenteeism, hospital fees, and international trade losses. ${ }^{10}$ The full health effects, as well as the full economic costs of consuming unsafe food, are not well known, but the global impact on health, trade, and development is considered enormous. ${ }^{9}$

According to the World Health Organization (WHO), ${ }^{8}$ approximately 600 million people worldwide become ill after consuming contaminated food every year. Among these victims, an estimated 420,000 die, including 125,000 children under the age of 5 years. ${ }^{6}$ However, cases of food infections and food poisoning are often underreported. Relative to their population, low- and middle-income countries in South Asia, Southeast Asia, and sub-Saharan Africa have a high burden of FBDs. They account for $53 \%$ of all food-borne illnesses and $75 \%$ of related deaths. ${ }^{10,11}$

The highest burden of foodborne-related illnesses was reported as 1300 disability-adjusted life-years (DALYs) per 100,000 population in the sub-Saharan African region. ${ }^{89}$ Approximately $10-20 \%$ of FBD outbreaks are due to contamination by the food handler. ${ }^{9,11}$ However, food safety, along with its health and economic benefits, has received little attention in diarrheal disease and other food infection control programs in Africa. ${ }^{11,12}$

In Ethiopia, there were 280,458 outpatient cases in $2013 .{ }^{13}$ In a study of 1225 pediatric patients attending outpatient clinics in Ethiopia, parasites were detected in 337 cases (30.7\%), Salmonella in 65 (5.3\%), and Shigella in 61 (4.9\%). Overall, these reports suggest the high toll on the public resulting from poor food safety practices. ${ }^{12,13}$

The food safety system in Ethiopia is not as organized and developed as in developed countries. Thereby, there are limited data on the burden of FBDs and food poisoning caused by poor food safety practices. Moreover, problems of the growing population, urbanization, lack of resources, lack of adequate knowledge, and poor attitude, are aggravating poor food hygiene and safety practice issues. ${ }^{13}$

Ethiopia has introduced a new initiative, the Health Extension Program (HEP), as a means of providing a comprehensive health service for the urban population, including food hygiene and safety, in health extension packages to prevent and control FBDs and food poisoning. As one strategy of this program, households have graduated as model families: household heads were selected and given basic training on the 16 health extension packages. ${ }^{14}$ The graduate model families were expected to demonstrate practical changes after receiving training on the packages.

However, there is no quantified evidence on whether the health extension strategy has had an effect on the prevalence of food safety practices and associated factors. Therefore, this study aimed to assess the prevalence and associated factors of food safety practices among health extension model and non-model households in Kombolcha.

\section{Methods}

\section{Study Setting}

The study was conducted in Kombolcha town, Amhara Region, Ethiopia (Figure 1). Kombolcha is located $375 \mathrm{~km}$ from Addis Ababa in the northeast direction and $485 \mathrm{~km}$ from the capital city of the Amhara region, Bahir Dar. It has a latitude and longitude of $11.050^{\circ} \mathrm{N}, 39.044^{\circ} \mathrm{E} / 11.083^{\circ} \mathrm{N} 39.733^{\circ} \mathrm{E}$, with an elevation between 1842 and $1915 \mathrm{~m}$ above sea level. Based on the 2017 national population projection conducted by the Central Statistics Agency of Ethiopia (CSA), Kombolcha district has a total population of 116,682 , of whom 58,480 are men and 58,202 women; 58,480 (50.12\%) are urban inhabitants living in the town of Kombolcha, and the rest of population lives in peri-urban kebeles around Kombolcha town. ${ }^{15}$

\section{Study Design and Period}

A community-based comparative cross-sectional study was conducted in selected kebeles of Kombolcha from April 15 to May 15, 2021.

\section{Study Participants}

The source population of the study was all households located in Kombolcha. The study participants were all selected household heads aged $>18$ years in randomly selected kebeles in the study area. 

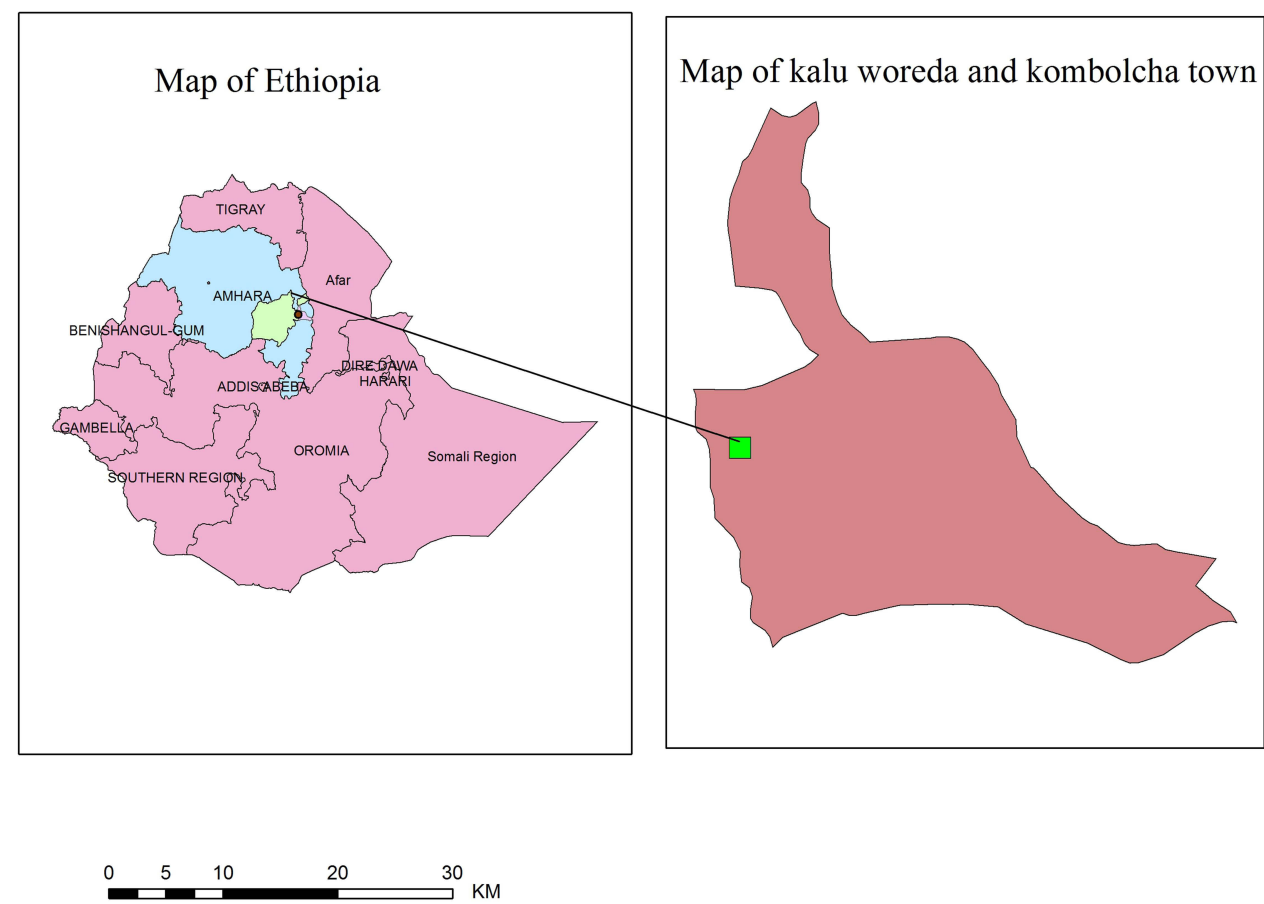

Figure I Map of the study area.

\section{Sample Size Determination}

The sample size needed for this study was calculated with the aim of detecting the difference between model and non-model households of $79 \%$ and $36.7 \%$, respectively, using the double population proportion formula. However, it was too small to generalize the results. To obtain an adequate sample size, a different sample size was calculated using commonly associated variables of food safety practices found in previous studies. Finally, the greatest sample size was obtained using the sex of the household head (one of the variables commonly associated with food safety practices). ${ }^{16}$ A power of $80 \%, 95 \%$ confidence interval (CI), taking the percentage outcome of food safety practices among male household heads as 30.4\%, the AOR for a female household head (1.63), and the ratio of exposed to unexposed as 1:1, were used to calculate the sample size using Epi Info 7 software. Finally, by adding a 10\% non-response rates, the final sample size was 672 households (336 for model and 336 for non-model households).

\section{Sampling Technique and Procedure}

There are 12 kebeles in the Kombolcha district, from which four kebeles were selected randomly. All 672 estimated participants were proportionally allocated to each kebele based on the respective numbers of households. A systematic random sampling method was used to select households based on the list of households in each kebele from the records of the health offices. However, for those households that had more than one model families, one model family memeber was selected randomly.

\section{Dependent and Independent Variables}

The dependent variable was food safety practices (good/poor). The data collection tool was organized into three parts: Part I contained socio-economic and demographic variables; Part II consisted of environmental, and behavioral factors; and Part III consisted of food safety practice measurement indicators. 


\section{Operational Definitions}

\section{Health Extension Packages}

As a preventive health program, the HEP promotes four areas of care, comprising disease prevention and control; family health; hygiene and environmental sanitation (excreta disposal, solid and liquid waste disposal, water supply and safety measures, food hygiene and safety measures, healthy home environment; and personal hygiene); and health education and communication.

\section{Model Household}

Households heads who attended above $75 \%$ of the training or 96 hours of the 16 health extension packages were certified as model households (observation of the certificate was mandatory).

\section{Non-Model Household}

Household heads who had not received basic training on the 16 health extension packages and/or who had attended below $75 \%$ of the training or 96 hours of the 16 health extension packages were defined as non-model households.

\section{Food Safety Practices}

These were determined using six food safety practice measurement indicators; namely, always washing hands before food preparation, washing food utensils and/or food, using improved water sources to prepare food, storing food in a covered container, keeping cooked and raw food separately, and elevating the container to place food and catering utensils where a child cannot reach them. ${ }^{5,17,18}$ Each criterion was given a value of 1 for a positive action of food safety practice or a correct response, and 0 for a negative action or an incorrect response. The sum of these assessment indicators was calculated and the mean score of all observations and interview questions was used as a cut-off point to categorize households into those having good or poor food safety practices. ${ }^{19}$ Those households practicing more than the mean score (4.19) of the six food safety practice assessment indicators were considered to have good food safety practices, and those households practicing less than or equal to the mean score (4.19) of the six food safety practice indicators were considered to have poor food safety practices.

\section{Knowledge}

Households reporting more than the mean score (3.27) of the six knowledge assessment indicators ${ }^{7,20-23}$ were considered to have good knowledge, whereas households reporting less than or equal to the mean score (3.27) of the knowledge assessment indicators were considered to have poor knowledge.

\section{Attitude}

Households with more than the mean score (6.43) of cumulative responses on 10 attitude measurement indicators were considered to have a good attitude, whereas households with less than or equal to the mean score (6.43) of cumulative responses on 10 attitude measurement indicators were considered to have a poor attitude.

\section{Improved Latrine}

Households with a pour-flush latrine piped to a sewer system, ventilated improved pit latrine (VIPL), pit latrine with slab, or composting toilet, in the dwelling or yard/compound, were classed as having an improved latrine.

\section{Unimproved Latrine}

Households with no latrine or toilet facility or a bucket system, an open latrine, outside yard/compound, shared private facility of any type, outside yard/compound, or shared public facility of any type, or practicing open defecation, were classed as having an unimproved latrine.

\section{Liquid Waste Disposal}

Proper disposal of liquid waste includes a soaking pit, cesspool, or septic tank, compost, and disposal in a designated site, whereas discharge into an open field was considered as improper liquid waste disposal. 


\section{Solid Waste Disposal}

Proper disposal of solid waste includes burning, burial in a pit, use as compost, and disposal in a designated site, whereas disposal in an open field was considered as improper solid waste disposal.

\section{Data Collection and Quality Assurance}

A structured questionnaire and observational checklist were adapted from related literature. ${ }^{5,24}$ The questionnaire was first prepared in English, then translated to Amharic (local language), and translated back to English to ensure consistency.

Six female environmental health officers who had a bachelor's degree and long experience in data collection were recruited as data collectors. A training manual was also prepared to facilitate the training process. Three days of extensive training were given to the data collectors and supervisors by the principal investigator before the start of the data collection process. The training was mainly focused on interviewing techniques and detailed discussion on each question, including those questions that needed careful attention and observation. Classroom lectures, mock interviews, and field practice were included in the training.

A pretest was conducted using a 5\% $(n=34)$ sample size of the total study sample in Haik town, near Kombolcha, to establish face validity and to ensure that the study participants understood what the investigators intended to measure. The pretest was performed by the data collectors to acquaint them with the questionnaire and give them further experience with data collection. The questionnaire was amended based on the results of the pretest.

The six environmental health officers administered the pretested, structured questionnaire by face-to-face interviews with household heads. They also observed participants' food safety practices. During data collection, if the participant was not available at the time of the first visit, the data collectors made another visit to that household on the next day. If they were unavailable again at the second visit, the household was considered as a non-respondent.

Two environmental health experts with a master's degree were involved in supervision. The supervisors were trained together with the data collectors, although the supervisors were separately taught how to supervise the data collectors and how to check the completed questionnaires, for instance, checking for inconsistencies in responses. Supervision was performed thoroughly for data quality control. The completed questionnaires were checked every day before data entry by the supervisors and/or principal investigator for completeness, clarity, and consistency. Any mistakes detected were corrected the next day.

\section{Statistical Analysis}

Data were entered thoroughly using EpiData version 3.1 and exported to SPSS version 25.0 for data cleaning and analysis. Quality control measures, including data cleaning using sorting, graphical exploration of distributions, crosstabulations, and summary statistics, were performed. A principal component analysis was used to construct a household wealth index (lowest, medium, and highest) after checking its assumptions for communality value $>0.5$, KMO (sampling adequacy) $>0.5$ with $p$-value $<0.05$, and complex structure factor (eigenvalue) $>1$. Descriptive statistics were used for categorical variables and mean $\pm \mathrm{SD}$ (standard deviation) for continuous variables. Continuous variables were categorized using information from the literature, and categorical variables were recategorized accordingly.

Binary logistic regression was used to examine the statistical association between explanatory variables and food safety practices at the household level. From the bivariable logistic regression analysis, variables with $p<0.25$ were selected as candidate variables for multivariable analysis. Bivariable (crude odds ratio [COR]) and multivariable (adjusted odds ratio [AOR]) logistic regression analyses were conducted and the results presented with 95\% CIs. From the multivariable logistic regression analysis, variables with a significance level of $p<0.05$ were considered statistically significant and independently associated with good food safety practices.

Multi-collinearity among independent variables was checked using the standard error with a cut-off value of 2, and none of the variables was found to be collinear, with the maximum standard error reported being 0.27 for good food safety practices as an outcome of interest. Model fitness was also checked using the Hosmer-Lemeshow test, which had a $p$-value $>0.05$, and the reported Hosmer-Lemeshow test $p$-value was 0.14 . 


\section{Results}

\section{Socio-Demographic Characteristics of the Study Participants}

A total of 656 households, 327 from health extension model and 329 from health extension non-model households, participated in the study, with a response rate of $97.62 \%$. Among these participants, 218 (66.7\%) were female, and the mean ages $( \pm \mathrm{SD})$ of model households and non-model households were comparable, at $32 \pm 8.47$ and $32 \pm 9.03$ years, respectively. Regarding their educational status, $11.3 \%$ and $10.9 \%$ of model households and non-model households, respectively, could not read and write, whereas only $17.1 \%$ of model households and $14.6 \%$ of non-model households had attended secondary level education (Table 1).

Table I Socio-Demographic Characteristics of Study Households in Kombolcha, Northeastern Ethiopia, 202 I

\begin{tabular}{|c|c|c|c|c|c|c|}
\hline \multicolumn{5}{|c|}{ Household Type } & \multirow{2}{*}{\multicolumn{2}{|c|}{ Total }} \\
\hline \multirow[t]{2}{*}{ Variables } & \multicolumn{2}{|c|}{ Model } & \multicolumn{2}{|c|}{ Non-Model } & & \\
\hline & Frequency & (\%) & Frequency & (\%) & Frequency & (\%) \\
\hline \multicolumn{7}{|l|}{ Age (years) } \\
\hline $18-27$ & 126 & 38.5 & 66 & 20.1 & 192 & 29.3 \\
\hline $28-37$ & 134 & 41.0 & 79 & 24.0 & 213 & 32.5 \\
\hline $38-47$ & 33 & 10.1 & 98 & 29.8 & $|3|$ & 20.0 \\
\hline$>47$ & 34 & 10.4 & 86 & 26.1 & 120 & 18.3 \\
\hline \multicolumn{7}{|l|}{ Sex of the respondents } \\
\hline Male & 109 & 33.3 & 112 & 34.0 & 221 & 33.7 \\
\hline Female & 218 & 66.7 & 217 & 66.0 & 435 & 66.3 \\
\hline \multicolumn{7}{|l|}{ Marital status } \\
\hline Currently unmarried & 167 & 51.1 & 176 & 53.5 & 343 & 52.3 \\
\hline Currently married & 160 & 48.9 & 153 & 46.5 & 313 & 47.7 \\
\hline \multicolumn{7}{|l|}{ Educational status } \\
\hline Unable to read and write & 37 & 11.3 & 36 & 10.9 & 73 & 11.1 \\
\hline Can read and write only & 64 & 19.6 & 70 & 21.3 & 134 & 20.4 \\
\hline Elementary education & 130 & 39.8 & 128 & 38.9 & 258 & 39.3 \\
\hline Secondary education & 56 & 17.1 & 48 & 14.6 & 104 & 15.9 \\
\hline College/university & 40 & 12.2 & 47 & 14.3 & 87 & 13.3 \\
\hline \multicolumn{7}{|l|}{ Economic status } \\
\hline Lowest & 107 & 32.7 & 116 & 35.3 & 223 & 34.0 \\
\hline Medium & III & 33.9 & 111 & 33.7 & 222 & 33.8 \\
\hline Highest & 109 & 33.3 & 102 & 31.0 & 211 & 32.2 \\
\hline \multicolumn{7}{|l|}{ Family size } \\
\hline$>5$ members & 73 & 22.3 & 90 & 27.4 & 163 & 24.8 \\
\hline$\leq 5$ members & 254 & 77.7 & 239 & 72.6 & 493 & 75.2 \\
\hline
\end{tabular}




\section{Environmental and Behavioral Factors}

Among model households, 136 (41.6\%) had functional hand-washing facilities, whereas 237 (72\%) of the non-model households had no functional hand-washing facilities. Of model households, 181 (55.4\%) disposed of liquid waste using properly constructed onsite sanitation management methods, including soak pits and septic tanks, while only $121(36.8 \%)$ of the non-model households disposed of liquid waste properly. Nearly half, 153 (46.8\%), of the model households, disposed of solid waste using properly constructed onsite sanitation management methods, including burning, burial in a pit, using as compost, and disposal in designated sites, but $260(79.0 \%)$ of the non-model households disposed of their liquid waste improperly using an open dumping method. Among model households, 245 (74.9\%) and 233 (71.3\%) had good knowledge of food safety practices and a good attitude towards food safety practices, respectively (Table 2).

\section{Food Safety Practice Measurement Indicators}

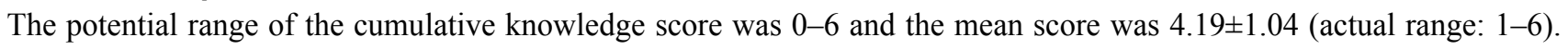
According to the reports from the study participants, the majority of households, $611(93.1 \%)$, used improved water sources to prepare food, $437(66.6 \%)$ always washed their hands before food preparation, $339(51.7 \%)$ always washed food utensils and/or food, 529 (80.6\%) stored food in a covered container, 369 (56.3\%) kept cooked and raw food separately, and $464(70.7 \%)$ of households used an elevated container in which to place food and catering utensils that a child cannot reach (Table 3).

Table 2 Environmental and Behavioral Factors of Food Safety Practices Among Health Extension Model and Non-Model Households in Kombolcha, Northeastern Ethiopia, 2021

\begin{tabular}{|c|c|c|c|c|c|c|}
\hline \multirow[t]{3}{*}{ Variables } & \multicolumn{4}{|c|}{ Household Type } & \multirow{2}{*}{\multicolumn{2}{|c|}{ Total }} \\
\hline & \multicolumn{2}{|c|}{ Model } & \multicolumn{2}{|c|}{ Non-Model } & & \\
\hline & Frequency & Percent (\%) & Frequency & Percent (\%) & Frequency & Percent (\%) \\
\hline \multicolumn{7}{|c|}{ Status of a latrine for use } \\
\hline Unimproved & 97 & 29.7 & 164 & 49.8 & 261 & 39.8 \\
\hline Improved & 230 & 70.3 & 165 & 50.2 & 395 & 60.2 \\
\hline \multicolumn{7}{|c|}{ Functional hand-washing facility } \\
\hline No & 191 & 58.4 & 237 & 72.0 & 428 & 65.2 \\
\hline Yes & 136 & 41.6 & 92 & 28.0 & 228 & 34.8 \\
\hline \multicolumn{7}{|c|}{ Liquid waste disposal } \\
\hline Improper & 146 & 44.6 & 208 & 63.2 & 354 & 54.0 \\
\hline Proper & 181 & 55.4 & 121 & 36.8 & 302 & 46.0 \\
\hline \multicolumn{7}{|c|}{ Solid waste disposal } \\
\hline Improper & 174 & 53.2 & 260 & 79.0 & 434 & 66.2 \\
\hline Proper & 153 & 46.8 & 69 & 21.0 & 222 & 33.8 \\
\hline \multicolumn{7}{|c|}{ Knowledge of food safety } \\
\hline Poor & 82 & 25.1 & 212 & 64.4 & 294 & 44.8 \\
\hline Good & 245 & 74.9 & 117 & 35.6 & 362 & 55.2 \\
\hline \multicolumn{7}{|c|}{ Attitude towards food safety practices } \\
\hline Poor & 94 & 28.7 & 202 & 61.4 & 296 & 45.1 \\
\hline Good & 233 & 71.3 & 127 & 38.6 & 360 & 54.9 \\
\hline
\end{tabular}


Table 3 Overall Food Safety Practices and Their Measurement Indicators Among Health Extension Model and Non-Model Households in Kombolcha, Northeastern Ethiopia, 2021

\begin{tabular}{|l|l|l|}
\hline \multirow{2}{*}{ Food Safety Practice Indicators } & \multicolumn{2}{l|}{ Response } \\
\cline { 2 - 3 } & No (\%) & Yes (\%) \\
\hline Do you always wash your hands before preparation? & $219(33.4 \%)$ & $437(66.6 \%)$ \\
\hline Do you always wash food utensils and/or food? & $317(48.3 \%)$ & $339(51.7 \%)$ \\
\hline Do you always use improved water sources to prepare food? & $45(6.9 \%)$ & $611(93.1 \%)$ \\
\hline Do you always store in a covered container? & $127(19.4 \%)$ & $529(80.6 \%)$ \\
\hline Do you always keep cooked and raw food separately? & $287(43.8 \%)$ & $369(56.3 \%)$ \\
\hline Do you always use an elevated container to place food and catering utensils (child cannot reach)? & $192(29.3 \%)$ & $464(70.7 \%)$ \\
\hline Overall food safety practice using mean score & Good & $\mathbf{2 9 3}(\mathbf{4 4 . 7 \% )}$ \\
\cline { 2 - 3 } & Poor & $\mathbf{3 6 3}(\mathbf{5 5 . 7 \% )}$ \\
\hline
\end{tabular}

\section{Prevalence of Food Safety Practices}

Out of 656 households, 293 (44.7\%; 95\% CI: 40.5-48.4\%) had good food safety practices, comprising 189 (57.8\%; 95\% CI: 53.0-63.1\%) of model households and 104 (31.6\%; 95\% CI: 26.5-36.7\%) of non-model households with good food safety practices, respectively. Since the prevalence confidence intervals did not overlap, we can conclude that there is a significant variation in food safety practices between the health extension model and non-model households (Figure 2).

\section{Factors Associated with Food Safety Practices Among Model Households}

From the multivariable analysis of split data collected from health extension model households, we found that female households (AOR: 4.95; 95\% CI: 2.77-8.86), and households with functional hand-washing facilities (AOR: 5.03; 95\% CI: 2.70-9.36), proper solid waste management (AOR: 4.21; 95\% CI: 2.26-7.83), and good knowledge (AOR: 5.40; 95\% CI: 2.94-9.95) were more likely to have good food safety practices than their counterparts.

\section{Factors Associated with Food Safety Practices Among Non-Model Households}

From the multivariable analysis of split data collected from health extension non-model households, we found that households with improved latrines (AOR: 3.34; 95\% CI: 1.96-5.69), functional hand-washing facilities (AOR: 2.15; 95\%

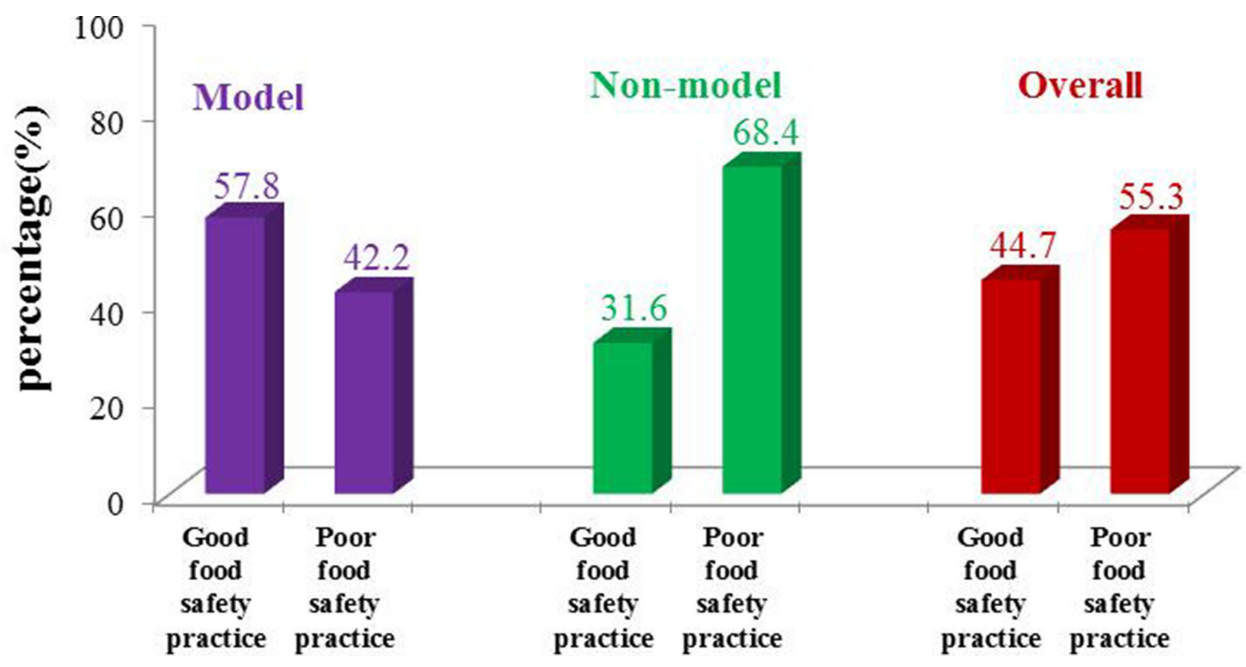

Figure 2 The prevalence of self-reported food safety practices among health extension model and non-model households in Kombolcha, Northeastern Ethiopia. 
CI: 1.21-3.83), and proper liquid waste management (AOR: 1.95 ; 95\% CI: $1.13-3.37$ ) were more likely to have good food safety practices than their counterparts.

\section{Factors Associated with Food Safety Practices from Pooled Data}

An overall multivariable logistic regression analysis was carried out to evaluate the combined effect of multiple associated factors by adjusting for confounding variables. The results indicated that being a model household, and having a female household head, proper solid waste management, and good knowledge of and a good attitude towards food safety practices, were significantly associated with good food safety practices.

In this study, model households were 2.99 times (AOR: 2.99; 95\% CI: 1.98-4.52) more likely to have good food safety practices than non-model households, whereas female households were 3.13 times (AOR: 3.13; 95\% CI: $2.13-$ 4.59) more likely to have good food safety practices than their counterparts. Households with proper solid waste management were 2.32 times (AOR: 2.32; 95\% CI: 1.54-3.48) more likely to have good food safety practices than households with improper solid waste management.

Those households with good knowledge were 2.05 times (AOR: 2.05; 95\% CI: 1.43-3.03) more likely to have good food safety practices than households with poor knowledge about food safety. The odds of good food safety practice among households with a good attitude towards food safety practice were 1.74 times (AOR: 1.74; 95\% CI: 1.22-2.49) higher than in households with a poor attitude (Table 4).

\section{Discussion}

Occurrences of food-borne illness and food poisoning are mainly attributed to a lack of knowledge on food safety and poor food safety practices, and are a major health problem in sub-Saharan Africa, including Ethiopia. ${ }^{12}$ To prevent this public health problem cost-effectively, the government of Ethiopia and other concerned stakeholders should emphasize knowledge of food safety and good safety practices at the household level. Therefore, this study generates evidence on the levels of food safety practices and their determinant factors among health extension model and non-model households in northeastern Ethiopia.

This study showed that there was a significantly higher prevalence of good food safety practices among model households compared to non-model households. This confirmed the results of previous studies conducted in Abobo district, Southwestern Ethiopia, and Hawassa City, Sidama, Ethiopia. ${ }^{16,25}$ Good food safety practices showed significant variation between model (57.8\%) and non-model households (31.6\%).

The reason for this large and significant variation may be that model families of the HEP were better implementers than non-model families, such that health extension workers gave more emphasis to training, practice, support, and follow-up on food safety measures to model households than to non-model households, and certified them as a model household when they fully applied all of the packages. This training and follow-up enabled them to bring knowledge and skills development to model households, which therefore had better food safety practices than non-model households.

The prevalence of good food safety practices among model households $(57.8 \%$; 95\% CI: $53.0-63.1 \%)$ in this study was lower than the prevalence of good food hygiene practices $(79 \%)$ among model households reported from a comparative cross-sectional study in Abobo district, Southwestern Ethiopia. This discrepancy may due to differences in the implementation of food safety measure packages, variations in time, differences in the study setting, variation in training, and the level of social acceptance of practices among model households. However, the level of good food safety practices among non-model households (31.6\%; 95\% CI: 26.5-36.7\%) was consistent with the findings (36.7\%) of a study conducted in Abobo district, Southwestern Ethiopia. ${ }^{16}$

The overall prevalence of good food safety practices among model and non-model households was $44.7 \%$ (95\% CI: $40.5-$ 48.4\%) and this prevalence was higher than in studies carried out in Northwest Ethiopia (40.1\%), ${ }^{20}$ Bole Sub-city in Addis Ababa (27.4\%), ${ }^{18}$ Arba Minch Town (32.6\%), ${ }^{22}$ and West Arsi Zone (27.5\%), Ethiopia, ${ }^{26}$ Imo State, Nigeria (37\%), ${ }^{27}$ and Lahore, Pakistan $(0.3 \%){ }^{28}$ This difference may be due to the improvements in health extension service approaches and other community health education services as interventions during the time gap between the studies. For instance, successive training on food hygiene and safety in the current study area could increase good food safety practices, since training is the best intervention through which to improve knowledge, which is a key factor in improving practice. 
Table 4 Bivariate and Multivariate Logistic Regression Analysis of Factors Associated with Food Safety Practices (FSP) Among Health Extension Model and Non-Model Households in Kombolcha, Northeastern Ethiopia, 202I

\begin{tabular}{|c|c|c|c|c|c|}
\hline \multirow[t]{2}{*}{ Variables } & \multicolumn{2}{|c|}{ FSP } & \multirow[t]{2}{*}{ COR $(95 \% \mathrm{Cl})$} & \multirow[t]{2}{*}{ AOR $(95 \% \mathrm{Cl})$} & \multirow[t]{2}{*}{$p$-Value } \\
\hline & Good & Poor & & & \\
\hline \multicolumn{6}{|c|}{ Household type } \\
\hline Model & 189 & 138 & $3.17(2.15-4.08)$ & $2.99(1.98-4.52)$ & $<0.001$ \\
\hline Non-model & 104 & 225 & I & 1 & \\
\hline \multicolumn{6}{|c|}{ Age of the respondents (years) } \\
\hline $18-27$ & 90 & 102 & I & I & \\
\hline $28-37$ & 99 & 114 & $0.97(1.51-3.14)$ & $0.98(0.63-1.53)$ & 0.917 \\
\hline $38-47$ & 61 & 70 & $1.24(0.69-2.22)$ & $1.88(1.09-3.19)$ & 0.210 \\
\hline$>47$ & 43 & 77 & $0.81(0.44-1.49)$ & $0.99(0.57-1.73)$ & 0.986 \\
\hline \multicolumn{6}{|c|}{ Sex of the respondents } \\
\hline Female & 228 & 207 & $2.64(1.87-3.73)$ & $3.13(2.13-4.59)$ & $<0.001$ \\
\hline Male & 65 & 156 & I & I & \\
\hline \multicolumn{6}{|c|}{ Economic status } \\
\hline Lowest & 104 & 119 & I & 1 & \\
\hline Medium & 106 & 116 & $1.05(0.72-1.52)$ & $1.13(0.74-1.72)$ & 0.574 \\
\hline Highest & 83 & 128 & $0.74(0.5 \mathrm{I}-\mathrm{I} .09)$ & $0.65(0.42-1.01)$ & 0.054 \\
\hline \multicolumn{6}{|c|}{ Status of a latrine for use } \\
\hline Improved & 227 & 168 & $1.24(0.91-1.7)$ & $1.69(1.17-2.46)$ & 0.056 \\
\hline Unimproved & 136 & 125 & I & $\mathrm{I}$ & \\
\hline \multicolumn{6}{|c|}{ Functional hand-washing facility } \\
\hline Yes & 116 & 112 & $1.47(1.06-2.03)$ & $1.20(0.83-1.75)$ & 0.333 \\
\hline No & 177 & 251 & I & I & \\
\hline \multicolumn{6}{|c|}{ Liquid waste management } \\
\hline Proper & 163 & 139 & $2.02(1.48-2.76)$ & $2.31(1.59-3.35)$ & $<0.001$ \\
\hline Improper & 130 & 224 & I & I & \\
\hline \multicolumn{6}{|c|}{ Solid waste management } \\
\hline Proper & 126 & 96 & $2.09(|.5|-2.9 \mid)$ & $2.32(1.54-3.48)$ & 0.640 \\
\hline Improper & 167 & 267 & I & 1 & \\
\hline \multicolumn{6}{|c|}{ Knowledge of food safety practices } \\
\hline Good & 178 & 184 & $1.51(1.10-2.06)$ & $2.05(1.43-3.03)$ & $<0.001$ \\
\hline Poor & 115 & 179 & I & I & \\
\hline
\end{tabular}

(Continued) 
Table 4 (Continued).

\begin{tabular}{|l|c|c|c|c|c|}
\hline \multirow{2}{*}{ Variables } & \multicolumn{2}{|c|}{ FSP } & \multirow{2}{*}{ COR (95\% CI) } & \multirow{2}{*}{ AOR (95\% CI) } & \multirow{2}{*}{$p$-Value } \\
\cline { 2 - 6 } & Good & Poor & & \\
\hline Attitude towards food safety practices & 185 & $1.43(1.05-1.95)$ & $1.74(1.22-2.48)$ & 0.002 \\
\hline Good & 175 & 1 & 1 & \\
\hline Poor & 118 & 178 & 1 & 1 \\
\hline
\end{tabular}

Note: I=reference category.

However, the prevalence of good food safety practices was lower than in other studies conducted in Ethiopia, in Gondar City (49.0\%), ${ }^{7}$ Debark Town (49.1\%), ${ }^{29}$ Dangila Town (52.5\%), ${ }^{30}$ Debre Markos Town (54\%), ${ }^{31}$ and in Paris, France $(65 \%){ }^{32}$ The discrepancy may also be due to the low performance in training and supervision on food safety measure packages and lower educational status of respondents (only $29.2 \%$ had above secondary education) compared to the previous studies, which, in turn, lowers the prevalence of good food safety practices in this study. This means that different local governments can increase the capacity of the community to actively participate in FBD prevention and control activities through implementing good food safety practices.

The multivariable logistic regression results showed that being a model household head (having received safety training) was a strong predictor of good food safety practices, which showed that the odds of performing good food safety practices among model household heads was 2.99 times higher compared to their counterparts. The result is corroborated by previous, similar studies, conducted in Debarq Town, ${ }^{29}$ Gondar City, ${ }^{7}$ Abobo district, ${ }^{16}$ and Hawassa City, South Ethiopia, ${ }^{25}$ Ghana, ${ }^{33}$ Bangladesh, ${ }^{34}$ Imo State, Nigeria, ${ }^{27}$ and Saudi Arabia. ${ }^{35}$ This could be explained by household heads who have received food safety training having a better understanding of safe food handling practices compared to household heads without food safety training.

Female household heads also had a greater likelihood of having good food safety practices than their male counterparts, similarly to a previous study. ${ }^{16}$ This indicates that female household heads accept food safety training and practices more readily than male household heads. Households with proper solid waste management were more likely to have good food safety practices than those with improper solid waste management, which confirms the results of previous, similar studies. ${ }^{16,36}$ A possible reason for this association is that food waste is a type of solid waste which can cause food contamination if it is improperly disposed of. To keep food safe, it is important to manage food waste and other solid wastes according to the recommended regulations.

The odds of performing good food safety practices among the study participants who had good knowledge of food safety practices was 2.05 times higher than in respondents who had poor knowledge. This study finding was also seen in previous studies carried out in Shashemene Town, Central Ethiopia, ${ }^{26}$ Bole Sub-city, Addis Ababa, ${ }^{18}$ Debre Markos Town, Ethiopia, ${ }^{31}$ Dangila Town, ${ }^{30}$ Gondar City, ${ }^{7}$ and Debarq Town, Northwest Ethiopia, ${ }^{29}$ Ghana, ${ }^{1}$ Imo State, Nigeria, ${ }^{27}$ Bangladesh, ${ }^{34}$ Jordan, ${ }^{37}$ and Sarawak and Petaling Jaya, Malaysia. ${ }^{38,39}$ This association indicated that food safety practices are highly influenced by increasing knowledge scores regarding food safety.

In this study, a good attitude towards food safety was also a significant predictor of good food safety practices. This finding is in line with results from cross-sectional studies conducted in Bole Sub-city, Addis Ababa, ${ }^{18}$ Northwest Ethiopia, ${ }^{20}$ Debarq Town ${ }^{29}$ and Debre Markos Town, Ethiopia, ${ }^{31}$ Imo State, Nigeria, ${ }^{27}$ Kuwait, ${ }^{40}$ Lahore, Pakistan, ${ }^{28}$ and Sarawak and Petaling Jaya, Malaysia. ${ }^{38,39}$ A possible reason for this association is that training in food safety measure packages leads to a good attitude, which may improve the behavior around and practice of food safety.

\section{Limitations}

This study was not without limitations, which should be considered in the interpretation of our findings. This study employed a cross-sectional research design, which limits the establishment of causal pathways. Owing to the specific study areas explored in this study, the findings may not be generalizable to the whole of Ethiopia. However, food safety 
practices were assessed by information provided by the respondents and standardized observational checklists, which may reduce reporting bias.

\section{Conclusions}

The overall prevalence of food safety practices among households was not satisfactory in the study area, despite significant variation between model and non-model households. The results showed that the prevalence of food safety practices among model households has not made good progress compared to the national Health Extension Program targets. Furthermore, food safety practices among non-model households are too low and continue to be a public health problem.

Being a model household, and having a female household head, proper solid waste management, and good knowledge of and attitude towards food safety were significantly associated with good food safety practices among households. Interventions should focus on the identified determinant factors during food safety and hygiene education programs. Continuous supportive supervision is required to enhance the knowledge and skills of food handlers to comply with better food safety practices. Regular audits should also be implemented to ensure the permanence of effective and continuous health extension training.

\section{Abbreviations}

AOR, adjusted odds ratio; CI, confidence interval; COR, crude odds ratio; FBD, food-borne disease; HEP, Health Extension Program; WHO, World Health Organization.

\section{Data Sharing Statement}

The data sets used and/or analyzed during the current study are available from the corresponding author and upon reasonable request.

\section{Ethical Approval and Consent}

The study was conducted in accordance with the Declaration of Helsinki. The ethical approval letter was obtained from the Institutional Ethical Review Committee of the College of Medicine and Health Sciences of Wollo University with the issue number of CMHS/366/13/21. Owing to the presence of illiterate participants, verbal informed consent, rather than written, was obtained from the participants before the commencement of data collection. The verbal consent process was approved by the Institutional Ethical Review Committee of the College of Medicine and Health Sciences of Wollo University, and each participant's consent was recorded as the data collectors informed them that their information would not be used for purposes other than scientific research and would be not disclosed to any third party. Participants were informed that participation would be voluntary and that they could withdraw at any time for any reason. Confidentiality and anonymity were maintained by avoiding possible identifiers such as the names of the study participants, by using identification numbers as a reference. Finally, health education was given to the study participants about good food safety practices after the data collection had ended.

\section{Acknowledgments}

The authors express their heartfelt gratitude to Wollo University for funding and the woreda health officers for giving valuable information for this study. We are also grateful to the data collectors, supervisors, and woreda administrators.

\section{Funding}

This research was supported by Wollo University (grant no: WU/2442/I.01/13).

\section{Disclosure}

All authors declare that they have no competing interests in this work. 


\section{References}

1. Akabanda F, Hlortsi EH, Owusu-kwarteng J. Food safety knowledge, attitudes and practices of institutional food-handlers in Ghana. BMC Public Health. 2017;17(40):1-9. doi:10.1186/s12889-016-3986-9

2. Annor GA, Baiden EA. Evaluation of food hygiene knowledge attitudes and practices of food handlers in food businesses in Accra, Ghana. Food Nutr Sci. 2016;2:830-836. doi:10.4236/fns.2011.28114

3. Scurrah K. Make it safe: a guide to food safety; 2010.

4. Norman G, Robert B. Principle of Food Sanitation. 5th ed. 2006.

5. Kleinau G. Strategic report 8 assessing hygiene improvement guidelines for household and community levels; 2004.

6. FAO/WHO. The future of food safety. Addis Ababa; 2019.

7. Azanaw J, Gebrehiwot M, Dagne H. Factors associated with food safety practices among food handlers: facility - based cross - sectional study. BMC Res Notes. 2019;12(683):2-6. doi:10.1186/s13104-019-4702-5

8. World Health Organization. Food-borne disease burden epidemiology reference group. Encycl Parasitol. 2015;1. doi:10.1007/978-3-642-277696 3884-1

9. Grace D. Food safety in low and middle income countries. Int J Environ Res Public Health. 2015;12(9):10490-10507. doi:10.3390/ ijerph120910490

10. World Health Orgnaization. Food safety and health: a strategy for the WHO African Region; 2007:57.

11. Ncube F, Kanda A, Chijokwe M, Mabaya G, Nyamugure T. Food safety knowledge, attitudes and practices of restaurant food handlers in a lowermiddle-income country. Food Sci Nutr. 2020;8(3):1677-1687. doi:10.1002/fsn3.1454

12. Mensah P, Mwamakamba L. Public health and food safety in the WHO African region. African J Food Agric Nutr Dev. 2012;12(4):6317-6335. doi:10.18697/ajfand.52.WHO-6

13. Ayalew H. Review on food safety system: Ethiopian perspective. African J Food Sci. 2013;7(12):431-440. doi:10.5897/ajfs2013.1064

14. FMOH. Annual performance health sector development Plan-III; 2007.

15. CSA. Population projection of Ethiopia for all regions at wereda level from $2014-2017$; 2017:1-118.

16. Okugn A, Woldeyohannes D. Food hygiene practices and its associated factors among model and non model households in Abobo district, southwestern Ethiopia: comparative cross-sectional study. PLoS one. 2018;13(4):1-9.

17. Woldt M, Moy GG. Literature review on effective food hygiene interventions for households in developing countries. Washington, DC; 2015. Available from: https://www.fantaproject.org/sites/default/files/resources/FoodHygieneLiteratureReview.pdf\%0Ahttp://www.fantaproject.org/sites/ default/files/resources/FoodHygieneLiteratureReview.pdf. Accessed February 18, 2022.

18. Abdi AM, Amano A, Abrahim A, Getahun M, Ababor S, Kumie A. Food hygiene practices and associated factors among food handlers working in food establishments in the bole sub city, Addis Ababa, Ethiopia. Risk Manag Healthc Policy. 2020;13:1861-1868. doi:10.2147/RMHP.S266342

19. Girmay AM, Gari SR, Mengistie Alemu B, Evans MR, Gebremariam AG. Determinants of sanitation and hygiene status among food establishments in Addis Ababa, Ethiopia. Environ Health Insights. 2020;14:1-9. doi:10.1177/1178630220915689

20. Chekol FA, Melak MF, Belew AK, Zeleke EG, Chekol FA. Food handling practice and associated factors among food handlers in public food establishments, Northwest Ethiopia. BMC Res Notes. 2019;12(20):1-7. doi:10.1186/s13104-019-4047-0

21. Gizaw Z, Gebrehiwot M. Food safety practice and associated factors of food handlers working in substandard food establish- ments in Gondar Town, Northwest Ethiopia. Int J Food Sci Nutr Diet. 2014;3(7):138-146.

22. Legesse D, Tilahun M, Agedew E, Haftu D. Food handling practices and associated factors among food handlers in arba minch town public food establishments in Gamo Gofa Zone, Southern Ethiopia. Epidemiol Open Access. 2017;07(02). doi:10.4172/2161-1165.1000302

23. Lema K, Abuhay N, Kindie W, Dagne H, Guadu T. Food hygiene practice and its determinants among food handlers at university of Gondar, northwest Ethiopia, 2019. Int J Gen Med. 2020;13:1129-1137. doi:10.2147/IJGM.S262767

24. Bartram J, Brocklehurst C, Fisher MB, et al. Global monitoring of water supply and sanitation: history, methods and future challenges. Int $J$ Environ Res Public Health. 2014;11(8):8137-8165. doi:10.3390/ijerph110808137

25. Berhe F, Berhane Y. Under five diarrhea among model household and non model households in Hawassa, South Ethiopia: a comparative crosssectional community based survey. BMC Public Health. 2014;14. doi:10.1186/1471-2458-14-187

26. Tesfay A, Tegegne Y. Assessment of food hygiene and safety practices among street food vendors and its associated factors in urban areas of Shashemane, West Arsi Zone, Oromia, Ethiopia. Sci J Immunol Immunother Res. 2020;4(1):1-5.

27. Iwu AC, Uwakwe K, Duru CB, et al. Knowledge, attitude and practices of food hygiene among food vendors in Owerri, Imo State, Nigeria. Occup Dis Environ Med. 2017;05(01):11-25. doi:10.4236/odem.2017.51002

28. Naeem N, Raza S, Mubeen H, Siddiqui SA, Khokhar R. Food safety knowledge, attitude, and food handling practices of household women in Lahore. J Food Saf. 2018;38(5):1-7. doi:10.1111/jfs.12513

29. Dagne H, Raju RP, Andualem Z, Hagos T, Addis K. Food safety practice and its associated factors among mothers in Debarq Town, Northwest Ethiopia: community-Based Cross-Sectional Study. Biomed Res Int. 2019;2019:1-8. doi:10.1155/2019/1549131

30. Ayehu Gashe Tessema KAG. Factors affecting food handling Practices among food handlers of Dangila town food and drink. BMC Public Health. 2014;14(571):1-5. doi:10.1186/1471-2458-14-1

31. Alemayehu T, Aderaw Z, Giza M, Diress G. Food safety knowledge, handling practices and associated factors among food handlers working in food establishments in debre markos town, northwest Ethiopia, 2020: institution-based cross-sectional study. Risk Manag Healthc Policy. 2021;14:1155-1163. doi:10.2147/RMHP.S295974

32. Czarniecka-skubina EWA, Trafiałek J, Wiatrowski M. An evaluation of the hygiene practices of European street food vendors and a preliminary estimation of food safety for consumers, conducted in Paris. J Food Prot. 2018;81(10):1614-1621. doi:10.4315/0362-028X.JFP-18-165

33. Tuglo LS, Agordoh PD, Tekpor D, Pan Z, Agbanyo G, Chu M. Food safety knowledge, attitude, and hygiene practices of street-cooked food handlers in North Dayi District, Ghana. Environ Health Prev Med. 2021;26(1):1-13. doi:10.1186/s12199-021-00975-9

34. Al Banna MH, Disu TR, Kundu S, et al. Factors associated with food safety knowledge and practices among meat handlers in Bangladesh: a crosssectional study. Environ Health Prev Med. 2021;26(1):1-12. doi:10.1186/s12199-021-01004-5

35. Alqurashi NA, Priyadarshini A, Jaiswal AK. Evaluating food safety knowledge and practices among foodservice staff in Al Madinah Hospitals, Saudi Arabia. Safety. 2019;5(1):1-19. doi:10.3390/safety5010009 
36. Gebru T, Taha M, Kassahun W. Risk factors of diarrhoeal disease in under-five children among health extension model and non-model families in Sheko district rural community, Southwest Ethiopia: comparative cross-sectional study. BMC Public Health. 2014;14(1):1-6. doi:10.1186/14712458-14-395

37. Osaili TM, Al-Nabulsi A, Taybeh AO. Food safety knowledge, attitudes, and practices among Jordan universities students during the COVID-19 pandemic. Front Public Heal. 2021;9(August):1-13. doi:10.3389/fpubh.2021.729816

38. Mohlisi U, Asmawi M, Norehan AA, et al. Current research in nutrition and food science an assessment of knowledge, attitudes and practices in food safety among food handlers engaged in food courts. Curr Res Nutr Food Sci. 2018;06(2):347-353.

39. Jores D, Arif MT, Rahman M. Factors associated with food hygiene practices among street food vendors in Padawan, Sarawak. Borneo J Resour Sci Technol. 2018;8(1):56-65. doi:10.33736/bjrst.824.2018

40. Al-Kandari D, Al-abdeen J, Sidhu J. Food safety knowledge, attitudes and practices of food handlers in restaurants in Kuwait. Food Control. 2019;103:103-110. doi:10.1016/j.foodcont.2019.03.040

\section{Publish your work in this journal}

Risk Management and Healthcare Policy is an international, peer-reviewed, open access journal focusing on all aspects of public health, policy, and preventative measures to promote good health and improve morbidity and mortality in the population. The journal welcomes submitted papers covering original research, basic science, clinical \& epidemiological studies, reviews and evaluations, guidelines, expert opinion and commentary, case reports and extended reports. The manuscript management system is completely online and includes a very quick and fair peer-review system, which is all easy to use. Visit http://www.dovepress.com/testimonials.php to read real quotes from published authors.

Submit your manuscript here: https://www.dovepress.com/risk-management-and-healthcare-policy-journal 